\title{
Weak convergence theorems for common solutions of a system of equilibrium problems and operator equations involving nonexpansive mappings
}

\author{
Peng Cheng ${ }^{1 *}$ and Anshen Zhang ${ }^{2}$
}

\author{
"Correspondence: \\ hschengp@yeah.net \\ 'School of Mathematics and \\ Information Science, North China \\ University of Water Resources and \\ Electric Power, Zhengzhou, 450011, \\ China \\ Full list of author information is \\ available at the end of the article
}

\begin{abstract}
In this paper, a monotone variational inequality, a system of equilibrium problems, and nonexpansive mappings are investigated based on an iterative algorithm. Weak convergence theorems of common solutions are established in Hilbert spaces.
\end{abstract}

AMS Subject Classification: 47H05; 47H09; 47J25

Keywords: equilibrium problem; monotone mapping; nonexpansive mapping; projection; variational inequality

\section{Introduction}

Equilibrium problems which were introduced by Blum and Oettli [1] have intensively been studied. It has been shown that equilibrium problems cover fixed point problems, variational inequality problems, inclusion problems, saddle problems, complementarity problem, minimization problem, and Nash equilibrium problem; see [1-3] and the references therein. Equilibrium problem has emerged as an effective and powerful tool for studying a wide class of problems which arise in economics, finance, image reconstruction, ecology, transportation, network, elasticity, and optimization; see [4-7] and the references therein. For the existence of solutions of equilibrium problems, we refer the readers to [8-13] and the references therein. However, from the standpoint of real world applications, it is important not only to know the existence of solutions of equilibrium problems, but also to be able to construct an iterative algorithm to approximate their solutions. The computation of solutions is important in the study of many real world problems. For instance, in computer tomography with limited data, each piece of information implies the existence of a convex set in which the required solution lies. The problem of finding a point in the intersection of a finite of the convex sets is then of crucial interest and it cannot be directly solved. Therefore, an iterative algorithm must be used to approximate such a point. The well-known convex feasibility problem which captures applications in various disciplines such as image restoration and radiation therapy treatment planning is to find a point in the intersection of common fixed point sets of a family of nonlinear mappings; see, for example, [14-19].

( 2013 Cheng and Zhang; licensee Springer. This is an Open Access article distributed under the terms of the Creative Commons Attribution License (http://creativecommons.org/licenses/by/2.0), which permits unrestricted use, distribution, and reproduction in any medium, provided the original work is properly cited. 
In this paper, a monotone variational inequality, a system of equilibrium problems, and nonexpansive mappings are investigated based on an iterative algorithm. Weak convergence theorems of common solutions are established in Hilbert spaces.

\section{Preliminaries}

In what follows, we always assume that $H$ is a real Hilbert space with the inner product $\langle\cdot, \cdot\rangle$ and the norm $\|\cdot\|$, and $C$ is a nonempty closed and convex subset of $H$.

Let $\mathbb{R}$ denote the set of real numbers and $F$ a bifunction of $C \times C$ into $\mathbb{R}$. Recall the bifunction equilibrium problem is to find an $x$ such that

$$
F(x, y) \geq 0, \quad \forall y \in C
$$

In this paper, the solution set of the equilibrium problem is denoted by $E P(F)$, i.e.,

$$
E P(F)=\{x \in C: F(x, y) \geq 0, \forall y \in C\} .
$$

To study the equilibrium problems (2.1), we may assume that $F$ satisfies the following conditions:

(A1) $F(x, x)=0$ for all $x \in C$;

(A2) $F$ is monotone, i.e., $F(x, y)+F(y, x) \leq 0$ for all $x, y \in C$;

(A3) for each $x, y, z \in C$,

$$
\limsup _{t \downarrow 0} F(t z+(1-t) x, y) \leq F(x, y)
$$

(A4) for each $x \in C, y \mapsto F(x, y)$ is convex and lower semi-continuous.

Let $S: C \rightarrow C$ be a mapping. In this paper, we use $F(S)$ to stand for the set of fixed points. Recall that the mapping $S$ is said to be nonexpansive if

$$
\|S x-S y\| \leq\|x-y\|, \quad \forall x, y \in C .
$$

If $C$ is a bounded closed and convex subset of $H$, then fixed point sets of nonexpansive mappings are not empty, closed, and convex; see [20] and the references therein.

Let $A: C \rightarrow H$ be a mapping. Recall that $A$ is said to be monotone if

$$
\langle A x-A y, x-y\rangle \geq 0, \quad \forall x, y \in C .
$$

A set-valued mapping $T: H \rightarrow 2^{H}$ is said to be monotone if, for all $x, y \in H, f \in T x$ and $g \in T y$ imply $\langle x-y, f-g\rangle>0$. A monotone mapping $T: H \rightarrow 2^{H}$ is maximal if the graph $G(T)$ of $T$ is not properly contained in the graph of any other monotone mapping. It is known that a monotone mapping $T$ is maximal if and only if, for any $(x, f) \in H \times H$, $\langle x-y, f-g\rangle \geq 0$ for all $(y, g) \in G(T)$ implies $f \in T x$. The class of monotone operators is one of the most important classes of operators. Within the past several decades, many authors have been devoted to the studies on the existence and convergence of zero points for maximal monotone operators. 
Let $F(x, y)=\langle A x, y-x\rangle, \forall x, y \in C$. We see that the problem (2.1) is reduced to the following classical variational inequality. Find $x \in C$ such that

$$
\langle A x, y-x\rangle \geq 0, \quad \forall y \in C
$$

It is known that $x \in C$ is a solution to (2.2) if and only if $x$ is a fixed point of the mapping $P_{C}(I-\rho A)$, where $\rho>0$ is a constant and $I$ is the identity mapping.

Recently, the common solution problems have been extensively studied by many scholars; see, for example, [21-33] and the references therein. In this paper, we investigate the common solution problem of a monotone variational inequality, a system of equilibrium problems, and nonexpansive mappings based on an iterative algorithm. In order to prove our main results, we need the following lemmas.

Lemma 2.1 Let $C$ be a nonempty closed and convex subset of $H$. Then the following inequality holds:

$$
\left\|x-\operatorname{Proj}_{C} x\right\|^{2}+\left\|y-\operatorname{Proj}_{C} y\right\|^{2} \leq\|x-y\|^{2}, \quad \forall x \in H, y \in C .
$$

Lemma 2.2 [1,2] Let $C$ be a nonempty closed convex subset of $H$ and $F: C \times C \rightarrow \mathbb{R}$ be a bifunction satisfying (A1)-(A4). Then, for any $r>0$ and $x \in H$, there exists $z \in C$ such that

$$
F(z, y)+\frac{1}{r}\langle y-z, z-x\rangle \geq 0, \quad \forall y \in C .
$$

Further, define

$$
T_{r} x=\left\{z \in C: F(z, y)+\frac{1}{r}\langle y-z, z-x\rangle \geq 0, \forall y \in C\right\}
$$

for all $r>0$ and $x \in H$. Then the following hold:

(a) $T_{r}$ is single-valued;

(b) $T_{r}$ is firmly nonexpansive, i.e., for any $x, y \in H$,

$$
\left\|T_{r} x-T_{r} y\right\|^{2} \leq\left\langle T_{r} x-T_{r} y, x-y\right\rangle
$$

(c) $F\left(T_{r}\right)=E P(F)$;

(d) $E P(F)$ is closed and convex.

Lemma 2.3 [33] Let $A$ be a monotone mapping of $C$ into $H$ and $N_{C} v$ be the normal cone to $C$ at $v \in C$, i.e.,

$$
N_{C} v=\{w \in H:\langle v-u, w\rangle \geq 0, \forall u \in C\}
$$

and define a mapping $T$ on $C$ by

$$
T v= \begin{cases}A v+N_{C} v, & v \in C, \\ \emptyset, & v \notin C .\end{cases}
$$

Then $T$ is maximal monotone and $0 \in T v$ if and only if $\langle A v, u-v\rangle \geq 0$ for all $u \in C$. 
Lemma 2.4 [34] Let $\left\{a_{n}\right\}_{n=1}^{N}$ be real numbers in $[0,1]$ such that $\sum_{n=1}^{N} a_{n}=1$. Then we have the following:

$$
\left\|\sum_{i=1}^{N} a_{i} x_{i}\right\|^{2} \leq \sum_{i=1}^{N} a_{i}\left\|x_{i}\right\|^{2}
$$

for any given bounded sequence $\left\{x_{n}\right\}_{n=1}^{N}$ in $H$.

Lemma 2.5 [35] Let $0<p \leq t_{n} \leq q<1$ for all $n \geq 1$. Suppose that $\left\{x_{n}\right\}$ and $\left\{y_{n}\right\}$ are sequences in $H$ such that

$$
\limsup _{n \rightarrow \infty}\left\|x_{n}\right\| \leq d, \quad \limsup _{n \rightarrow \infty}\left\|y_{n}\right\| \leq d
$$

and

$$
\lim _{n \rightarrow \infty}\left\|t_{n} x_{n}+\left(1-t_{n}\right) y_{n}\right\|=d
$$

hold for some $r \geq 0$. Then $\lim _{n \rightarrow \infty}\left\|x_{n}-y_{n}\right\|=0$.

Lemma 2.6 [36] Let $C$ be a nonempty closed and convex subset of $H$ and $S: C \rightarrow C$ be a nonexpansive mapping. If $\left\{x_{n}\right\}$ is a sequence in $C$ such that $x_{n} \rightarrow x$ and $\lim _{n \rightarrow \infty}\left\|x_{n}-S x_{n}\right\|=$ 0 , then $x=S x$.

Lemma 2.7 [37] Let $\left\{a_{n}\right\},\left\{b_{n}\right\}$, and $\left\{c_{n}\right\}$ be three nonnegative sequences satisfying the following condition:

$$
a_{n+1} \leq\left(1+b_{n}\right) a_{n}+c_{n}, \quad \forall n \geq n_{0}
$$

where $n_{0}$ is some nonnegative integer, $\sum_{n=1}^{\infty} b_{n}<\infty$, and $\sum_{n=1}^{\infty} c_{n}<\infty$. Then the limit $\lim _{n \rightarrow \infty} a_{n}$ exists.

\section{Main results}

Theorem 3.1 Let $C$ be a nonempty closed convex subset of $H, S: C \rightarrow C$ be a nonexpansive mapping with a nonempty fixed point set, and $A: C \rightarrow H$ be a L-Lipschitz continuous and monotone mapping. Let $F_{m}$ be a bifunction from $C \times C$ to $\mathbb{R}$ which satisfies (A1)-(A4). Let $N \geq 1$ denote some positive integer. Assume that $\mathcal{F}:=\bigcap_{m=1}^{N} \operatorname{EP}\left(F_{m}\right) \cap V I(C, A) \cap F(S)$ is not empty. Let $\left\{\alpha_{n}\right\},\left\{\beta_{n}\right\},\left\{\gamma_{n}\right\},\left\{\delta_{n, 1}\right\}, \ldots,\left\{\delta_{n, N}\right\}$ be real number sequences in $(0,1)$. Let $\left\{\lambda_{n}\right\}$, $\left\{r_{n, 1}\right\}, \ldots$, and $\left\{r_{n, N}\right\}$ be positive real number sequences. Let $\left\{e_{n}\right\}$ be a bounded sequence in $H$. Let $\left\{x_{n}\right\}$ be a sequence generated in the following manner:

$$
\left\{\begin{array}{l}
x_{1} \in H, \\
x_{n+1}=\alpha_{n} x_{n}+\beta_{n} S \operatorname{Proj}_{C}\left(\sum_{m=1}^{N} \delta_{n, m} z_{n, m}-\lambda_{n} A y_{n}\right)+\gamma_{n} e_{n}, \quad n \geq 1, \\
y_{n}=\operatorname{Proj}_{C}\left(\sum_{m=1}^{N} \delta_{n, m} z_{n, m}-\lambda_{n} A \sum_{m=1}^{N} \delta_{n, m} z_{n, m}\right),
\end{array}\right.
$$

where $z_{n, m}$ is such that

$$
F_{m}\left(z_{n, m}, z\right)+\frac{1}{r_{n, m}}\left\langle z-z_{n, m}, z_{n, m}-x_{n}\right\rangle \geq 0, \quad \forall z \in C, \forall m \in\{1,2 \ldots, N\}
$$


Assume that $\left\{\alpha_{n}\right\},\left\{\beta_{n}\right\},\left\{\gamma_{n}\right\},\left\{\delta_{n, 1}\right\}, \ldots,\left\{\delta_{n, N}\right\},\left\{\lambda_{n}\right\},\left\{r_{n, 1}\right\}, \ldots$, and $\left\{r_{n, N}\right\}$ satisfy the following restrictions:

(a) $\alpha_{n}+\beta_{n}+\gamma_{n}=1$,

(b) $0<a \leq \beta_{n} \leq b<1$ and $\sum_{n=1}^{\infty} \gamma_{n}<\infty$;

(c) $\sum_{m=1}^{N} \delta_{n, m}=1$ and $0<c \leq \delta_{n, m} \leq 1$;

(d) $\liminf _{n \rightarrow \infty} r_{n, m}>0$ and $d \leq \lambda_{n} \leq e$, where $d, e \in(0,1 / L)$.

Then the sequence $\left\{x_{n}\right\}$ weakly converges to some point $\bar{x} \in \mathcal{F}$.

Proof Put $u_{n}=\operatorname{Proj}_{C}\left(\sum_{m=1}^{N} \delta_{n, m} z_{n, m}-\lambda_{n} A y_{n}\right)$ and $v_{n}=\sum_{m=1}^{N} \delta_{n, m} z_{n, m}$. Letting $p \in \mathcal{F}$, we see from Lemma 2.1 that

$$
\begin{aligned}
\left\|u_{n}-p\right\|^{2} \leq & \left\|v_{n}-\lambda_{n} A y_{n}-p\right\|^{2}-\left\|v_{n}-\lambda_{n} A y_{n}-u_{n}\right\|^{2} \\
= & \left\|v_{n}-p\right\|^{2}-\left\|v_{n}-u_{n}\right\|^{2}+2 \lambda_{n}\left\langle A y_{n}, p-u_{n}\right\rangle \\
= & \left\|v_{n}-p\right\|^{2}-\left\|v_{n}-u_{n}\right\|^{2}+2 \lambda_{n}\left(\left\langle A y_{n}-A p, p-y_{n}\right\rangle+\left\langle A p, p-y_{n}\right\rangle\right. \\
& \left.+\left\langle A y_{n}, y_{n}-u_{n}\right\rangle\right) \\
\leq & \left\|v_{n}-p\right\|^{2}-\left\|v_{n}-u_{n}\right\|^{2}+2 \lambda_{n}\left\langle A y_{n}, y_{n}-u_{n}\right\rangle \\
= & \left\|v_{n}-p\right\|^{2}-\left\|v_{n}-y_{n}\right\|^{2}-\left\|y_{n}-u_{n}\right\|^{2}+2\left\langle v_{n}-\lambda_{n} A y_{n}-y_{n}, u_{n}-y_{n}\right\rangle .
\end{aligned}
$$

Notice that $A$ is $L$-Lipschitz continuous and $y_{n}=\operatorname{Proj}_{C}\left(v_{n}-\lambda_{n} A v_{n}\right)$. It follows that

$$
\begin{aligned}
\left\langle v_{n}\right. & \left.-\lambda_{n} A y_{n}-y_{n}, u_{n}-y_{n}\right\rangle \\
& =\left\langle v_{n}-\lambda_{n} A v_{n}-y_{n}, u_{n}-y_{n}\right\rangle+\left\langle\lambda_{n} A v_{n}-\lambda_{n} A y_{n}, u_{n}-y_{n}\right\rangle \\
& \leq \lambda_{n} L\left\|v_{n}-y_{n}\right\|\left\|u_{n}-y_{n}\right\| .
\end{aligned}
$$

Substituting (3.2) into (3.1), we obtain that

$$
\begin{aligned}
\left\|u_{n}-p\right\|^{2} & \leq\left\|v_{n}-p\right\|^{2}-\left\|v_{n}-y_{n}\right\|^{2}-\left\|y_{n}-u_{n}\right\|^{2}+2 \lambda_{n} L\left\|v_{n}-y_{n}\right\|\left\|u_{n}-y_{n}\right\| \\
& \leq\left\|v_{n}-p\right\|^{2}+\left(\lambda_{n}^{2} L^{2}-1\right)\left\|v_{n}-y_{n}\right\|^{2} .
\end{aligned}
$$

On the other hand, we have from the restriction (c) that

$$
\begin{aligned}
\left\|v_{n}-p\right\|^{2} & \leq\left\|\sum_{m=1}^{N} \delta_{n, m} z_{n, m}-p\right\|^{2} \\
& \leq \sum_{m=1}^{N} \delta_{n, m}\left\|z_{n, m}-p\right\|^{2} \\
& \leq \sum_{m=1}^{N} \delta_{n, m}\left\|T_{r_{n, m}} x_{n}-p\right\|^{2} \\
& \leq\left\|x_{n}-p\right\|^{2} .
\end{aligned}
$$

Substituting (3.4) into (3.3), we obtain that

$$
\left\|u_{n}-p\right\|^{2} \leq\left\|x_{n}-p\right\|^{2}+\left(\lambda_{n}^{2} L^{2}-1\right)\left\|v_{n}-y_{n}\right\|^{2} .
$$


This in turn implies from the restriction (d) that

$$
\begin{aligned}
\left\|x_{n+1}-p\right\|^{2} & \leq \alpha_{n}\left\|x_{n}-p\right\|^{2}+\beta_{n}\left\|S u_{n}-p\right\|^{2}+\gamma_{n}\left\|e_{n}-p\right\|^{2} \\
& \leq \alpha_{n}\left\|x_{n}-p\right\|^{2}+\beta_{n}\left\|u_{n}-p\right\|^{2}+\gamma_{n}\left\|e_{n}-p\right\|^{2} \\
& \leq \alpha_{n}\left\|x_{n}-p\right\|^{2}+\beta_{n}\left(\left\|x_{n}-p\right\|^{2}+\left(\lambda_{n}^{2} L^{2}-1\right)\left\|v_{n}-y_{n}\right\|^{2}\right)+\gamma_{n}\left\|e_{n}-p\right\|^{2} \\
& \leq\left\|x_{n}-p\right\|^{2}+\beta_{n}\left(\lambda_{n}^{2} L^{2}-1\right)\left\|v_{n}-y_{n}\right\|^{2}+\gamma_{n}\left\|e_{n}-p\right\|^{2} \\
& \leq\left\|x_{n}-p\right\|^{2}+\gamma_{n}\left\|e_{n}-p\right\|^{2} .
\end{aligned}
$$

It follows from Lemma 2.7 that the $\lim _{n \rightarrow \infty}\left\|x_{n}-p\right\|$ exists. This in turn shows that $\left\{x_{n}\right\}$ is bounded. It follows from (3.6) that

$$
\beta_{n}\left(1-\lambda_{n}^{2} L^{2}\right)\left\|v_{n}-y_{n}\right\|^{2} \leq\left\|x_{n}-p\right\|^{2}-\left\|x_{n+1}-p\right\|^{2}+\gamma_{n}\left\|e_{n}-p\right\|^{2} .
$$

This implies from the restrictions (b) and (d) that

$$
\lim _{n \rightarrow \infty}\left\|v_{n}-y_{n}\right\|=0
$$

Notice that

$$
\begin{aligned}
\left\|y_{n}-u_{n}\right\| & =\left\|\operatorname{Proj}_{C}\left(v_{n}-\lambda_{n} A v_{n}\right)-\operatorname{Proj}_{C}\left(v_{n}-\lambda_{n} A y_{n}\right)\right\| \\
& \leq\left\|\left(v_{n}-\lambda_{n} A v_{n}\right)-\left(v_{n}-\lambda_{n} A y_{n}\right)\right\| \\
& \leq \lambda L\left\|v_{n}-y_{n}\right\| .
\end{aligned}
$$

It follows from (3.7) that

$$
\lim _{n \rightarrow \infty}\left\|y_{n}-u_{n}\right\|=0
$$

In view of

$$
\left\|v_{n}-u_{n}\right\| \leq\left\|v_{n}-y_{n}\right\|+\left\|y_{n}-u_{n}\right\|,
$$

we see from (3.7) and (3.8) that

$$
\lim _{n \rightarrow \infty}\left\|v_{n}-u_{n}\right\|=0 \text {. }
$$

Notice that

$$
\begin{aligned}
\left\|z_{n, m}-p\right\|^{2} & =\left\|T_{r_{n, m}} x_{n}-T_{r_{n, m}} p\right\|^{2} \\
& \leq\left\langle T_{r_{n, m}} x_{n}-T_{r_{n, m}} p, x_{n}-p\right\rangle \\
& =\left\langle z_{n, m}-p, x_{n}-p\right\rangle \\
& =\frac{1}{2}\left(\left\|z_{n, m}-p\right\|^{2}+\left\|x_{n}-p\right\|^{2}-\left\|z_{n, m}-x_{n}\right\|^{2}\right), \quad \forall 1 \leq m \leq N .
\end{aligned}
$$


This implies that

$$
\left\|z_{n, m}-p\right\|^{2} \leq\left\|x_{n}-p\right\|^{2}-\left\|z_{n, m}-x_{n}\right\|^{2}, \quad \forall 1 \leq m \leq N
$$

In view of (3.10) and $v_{n}=\sum_{m=1}^{N} \delta_{n, m} z_{n, m}$, where $\sum_{m=1}^{N} \delta_{n, m}=1$, we see from Lemma 2.4 that

$$
\begin{aligned}
\left\|v_{n}-p\right\|^{2} & \leq \sum_{m=1}^{N} \delta_{n, m}\left\|z_{n, m}-p\right\|^{2} \\
& \leq \sum_{m=1}^{N} \delta_{n, m}\left(\left\|x_{n}-p\right\|^{2}-\left\|z_{n, m}-x_{n}\right\|^{2}\right) \\
& =\left\|x_{n}-p\right\|^{2}-\sum_{m=1}^{N} \delta_{n, m}\left\|z_{n, m}-x_{n}\right\|^{2} .
\end{aligned}
$$

In view of (3.3), we obtain from the restriction (d) that

$$
\begin{aligned}
\left\|x_{n+1}-p\right\|^{2} & \leq \alpha_{n}\left\|x_{n}-p\right\|^{2}+\beta_{n}\left\|S u_{n}-p\right\|^{2}+\gamma_{n}\left\|e_{n}-p\right\|^{2} \\
& \leq \alpha_{n}\left\|x_{n}-p\right\|^{2}+\beta_{n}\left\|u_{n}-p\right\|^{2}+\gamma_{n}\left\|e_{n}-p\right\|^{2} \\
& \leq \alpha_{n}\left\|x_{n}-p\right\|^{2}+\beta_{n}\left\|v_{n}-p\right\|^{2}+\gamma_{n}\left\|e_{n}-p\right\|^{2} \\
& \leq\left\|x_{n}-p\right\|^{2}-\beta_{n} \sum_{m=1}^{N} \delta_{n, m}\left\|z_{n, m}-x_{n}\right\|^{2}+\gamma_{n}\left\|e_{n}-p\right\|^{2} .
\end{aligned}
$$

It follows that

$$
\beta_{n} \delta_{n, m}\left\|z_{n, m}-x_{n}\right\|^{2} \leq\left\|x_{n}-p\right\|^{2}-\left\|x_{n+1}-p\right\|^{2}+\gamma_{n}\left\|e_{n}-p\right\|^{2}
$$

In view of the restrictions (b) and (c), we find that

$$
\lim _{n \rightarrow \infty}\left\|z_{n, m}-x_{n}\right\|=0
$$

Since $\left\{x_{n}\right\}$ is bounded, we may assume that a subsequence $\left\{x_{n_{i}}\right\}$ of $\left\{x_{n}\right\}$ converges weakly to $\xi$. It follows from (3.12) that $\left\{z_{n_{i}, m}\right\}$ converges weakly to $\xi$ for each $1 \leq m \leq N$. Next, we show that $\xi \in E P\left(F_{m}\right)$ for each $1 \leq m \leq N$. Since $z_{n, m}=T_{r_{n, m}} x_{n}$, we have

$$
F_{m}\left(z_{n, m}, z\right)+\frac{1}{r_{n, m}}\left\langle z-z_{n, m}, z_{n, m}-x_{n}\right\rangle \geq 0, \quad \forall z \in C .
$$

From the assumption (A2), we see that

$$
\frac{1}{r_{n, m}}\left\langle z-z_{n, m}, z_{n, m}-x_{n}\right\rangle \geq F_{m}\left(z, z_{n, m}\right), \quad \forall z \in C .
$$

Replacing $n$ by $n_{i}$, we arrive at

$$
\left\langle z-z_{n_{i}, m}, \frac{z_{n_{i}, m}-x_{n_{i}}}{r_{n_{i}, m}}\right\rangle \geq F_{m}\left(z, z_{n_{i}, m}\right), \quad \forall z \in C .
$$


In view of the assumption (A4), we get from (3.12) that

$$
F_{m}(z, \xi) \leq 0, \quad \forall z \in C
$$

For $t_{m}$ with $0<t_{m} \leq 1$ and $z \in C$, let $z_{t_{m}}=t_{m} z+\left(1-t_{m}\right) \xi$ for each $1 \leq m \leq N$. Since $z \in C$ and $\xi \in C$, we have $z_{t_{m}} \in C$ for each $1 \leq m \leq N$. It follows that $F_{m}\left(z_{t_{m}}, \xi\right) \leq 0$ for each $1 \leq m \leq N$. Notice that

$$
0=F_{m}\left(z_{t_{m}}, z_{t_{m}}\right) \leq t_{m} F_{m}\left(z_{t_{m}}, z\right)+\left(1-t_{m}\right) F_{m}\left(z_{t_{m}}, \xi\right) \leq t_{m} F_{m}\left(z_{t_{m}}, z\right), \quad \forall 1 \leq m \leq N
$$

which yields that

$$
F_{m}\left(z_{t_{m}}, z\right) \geq 0, \quad \forall z \in C
$$

Letting $t_{m} \downarrow 0$ for each $1 \leq m \leq N$, we obtain from the assumption (A3) that

$$
F_{m}(\xi, z) \geq 0, \quad \forall z \in C
$$

This implies that $\xi \in E P\left(F_{m}\right)$ for each $1 \leq m \leq N$. This proves that $\xi \in \bigcap_{m=1}^{N} E P\left(F_{m}\right)$.

Next, we show that $\xi \in V I(C, A)$. In fact, let $T$ be the maximal monotone mapping defined by

$$
T x= \begin{cases}A x+N_{C} x, & x \in C, \\ \emptyset, & x \notin C .\end{cases}
$$

For any given $(x, y) \in G(T)$, we have $y-A x \in N_{C} x$. So, we have $\langle x-m, y-A x\rangle \geq 0$, for all $m \in C$. On the other hand, we have $u_{n}=\operatorname{Proj}_{C}\left(v_{n}-\lambda_{n} A y_{n}\right)$. We obtain that

$$
\left\langle v_{n}-\lambda_{n} A y_{n}-u_{n}, u_{n}-x\right\rangle \geq 0
$$

and hence

$$
\left\langle x-u_{n}, \frac{u_{n}-v_{n}}{\lambda_{n}}+A y_{n}\right\rangle \geq 0 .
$$

In view of the monotonicity of $A$, we see that

$$
\begin{aligned}
\left\langle x-u_{n_{i}}, y\right\rangle \geq & \left\langle x-u_{n_{i}}, A x\right\rangle \\
\geq & \left\langle x-u_{n_{i}}, A x\right\rangle-\left\langle x-u_{n_{i}}, \frac{u_{n_{i}}-v_{n_{i}}}{\lambda_{n_{i}}}+A y_{n_{i}}\right\rangle \\
= & \left\langle x-u_{n_{i}}, A x-A u_{n_{i}}\right\rangle+\left\langle x-u_{n_{i}}, A u_{n_{i}}-A y_{n_{i}}\right\rangle \\
& -\left\langle x-u_{n_{i}}, \frac{u_{n_{i}}-v_{n_{i}}}{\lambda_{n_{i}}}\right\rangle \\
\geq & \left\langle x-u_{n_{i}}, A u_{n_{i}}-A y_{n_{i}}\right\rangle-\left\langle x-u_{n_{i}}, \frac{u_{n_{i}}-v_{n_{i}}}{\lambda_{n_{i}}}\right\rangle .
\end{aligned}
$$


On the other hand, we see that

$$
\left\|v_{n}-x_{n}\right\| \leq \sum_{m=1}^{N} \delta_{n, m}\left\|z_{n, m}-x_{n}\right\|
$$

It follows from (3.12) that

$$
\lim _{n \rightarrow \infty}\left\|v_{n}-x_{n}\right\|=0
$$

Notice that

$$
\left\|u_{n}-x_{n}\right\| \leq\left\|u_{n}-v_{n}\right\|+\left\|v_{n}-x_{n}\right\| .
$$

Combining (3.9) with (3.14), we arrive at

$$
\lim _{n \rightarrow \infty}\left\|u_{n}-x_{n}\right\|=0
$$

This in turn implies that $u_{n_{i}} \rightarrow \xi$. It follows from (3.13) that $\langle x-\xi, y\rangle \geq 0$. Notice that $T$ is maximal monotone and hence $0 \in T \xi$. This shows from Lemma 2.3 that $\xi \in V I(C, A)$.

Next, we show that $\xi \in F(S)$. Since $\lim _{n \rightarrow \infty}\left\|x_{n}-p\right\|$ exists, we put $\lim _{n \rightarrow \infty}\left\|x_{n}-p\right\|=$ $d>0$. It follows that

$$
\lim _{n \rightarrow \infty}\left\|x_{n+1}-p\right\|=\lim _{n \rightarrow \infty}\left\|\left(1-\beta_{n}\right)\left(x_{n}-p+\gamma_{n}\left(e_{n}-x_{n}\right)\right)+\beta_{n}\left(S u_{n}-p+\gamma_{n}\left(e_{n}-x_{n}\right)\right)\right\|=d .
$$

Notice that

$$
\begin{aligned}
\left\|S u_{n}-p+\gamma_{n}\left(e_{n}-x_{n}\right)\right\| & \leq\left\|S u_{n}-p\right\|+\gamma_{n}\left\|e_{n}-x_{n}\right\| \\
& \leq\left\|u_{n}-p\right\|+\gamma_{n}\left\|e_{n}-x_{n}\right\| \\
& \leq\left\|x_{n}-p\right\|+\gamma_{n}\left\|e_{n}-x_{n}\right\| .
\end{aligned}
$$

This shows that

$$
\limsup _{n \rightarrow \infty}\left\|S u_{n}-p+\gamma_{n}\left(e_{n}-x_{n}\right)\right\| \leq d
$$

On the other hand, we have

$$
\limsup _{n \rightarrow \infty}\left\|x_{n}-p+\gamma_{n}\left(e_{n}-x_{n}\right)\right\| \leq d .
$$

It follows from Lemma 2.5 that

$$
\lim _{n \rightarrow \infty}\left\|x_{n}-S u_{n}\right\|=0 .
$$

In view of

$$
\begin{aligned}
\left\|S x_{n}-x_{n}\right\| & \leq\left\|S x_{n}-S u_{n}\right\|+\left\|S u_{n}-x_{n}\right\| \\
& \leq\left\|x_{n}-u_{n}\right\|+\left\|S u_{n}-x_{n}\right\|,
\end{aligned}
$$


we find from (3.15) and (3.16) that

$$
\lim _{n \rightarrow \infty}\left\|x_{n}-S x_{n}\right\|=0
$$

This implies from Lemma 2.6 that $\xi \in F(S)$. This completes the proof that $\xi \in \mathcal{F}$.

Finally, we show that the whole sequence $\left\{x_{n}\right\}$ weakly converges to $\xi$. Let $\left\{x_{n_{j}}\right\}$ be another subsequence of $\left\{x_{n}\right\}$ converging weakly to $\xi^{\prime}$, where $\xi^{\prime} \neq \xi$. In the same way, we can show that $\xi^{\prime} \in \mathcal{F}$. Since the space $H$ enjoys Opial's condition, we, therefore, obtain that

$$
\begin{aligned}
d & =\liminf _{i \rightarrow \infty}\left\|x_{n_{i}}-\xi\right\|<\liminf _{i \rightarrow \infty}\left\|x_{n_{i}}-\xi^{\prime}\right\| \\
& =\liminf _{j \rightarrow \infty}\left\|x_{j}-\xi^{\prime}\right\|<\liminf _{j \rightarrow \infty}\left\|x_{j}-\xi\right\|=d .
\end{aligned}
$$

This is a contradiction. Hence, $\xi=\xi^{\prime}$. This completes the proof.

If $N=1$, then Theorem 3.1 is reduced to the following.

Corollary 3.2 Let $C$ be a nonempty closed convex subset of $H, S: C \rightarrow C$ be a nonexpansive mapping with a nonempty fixed point set, and $A: C \rightarrow H$ be a L-Lipschitz continuous and monotone mapping. Let $F$ be a bifunction from $C \times C$ to $\mathbb{R}$ which satisfies (A1)-(A4). Assume that $\mathcal{F}:=E P(F) \cap V I(C, A) \cap F(S)$ is not empty. Let $\left\{\alpha_{n}\right\},\left\{\beta_{n}\right\}$, and $\left\{\gamma_{n}\right\}$ be real number sequences in $(0,1)$. Let $\left\{\lambda_{n}\right\},\left\{r_{n}\right\}$ be positive real number sequences. Let $\left\{e_{n}\right\}$ be a bounded sequence in $H$. Let $\left\{x_{n}\right\}$ be a sequence generated in the following manner:

$$
\left\{\begin{array}{l}
x_{1} \in H, \\
x_{n+1}=\alpha_{n} x_{n}+\beta_{n} S \operatorname{Proj}_{C}\left(z_{n}-\lambda_{n} A y_{n}\right)+\gamma_{n} e_{n}, \quad n \geq 1, \\
y_{n}=\operatorname{Proj}_{C}\left(z_{n}-\lambda_{n} A z_{n}\right)
\end{array}\right.
$$

where $z_{n}$ is such that

$$
F\left(z_{n}, z\right)+\frac{1}{r_{n}}\left\langle z-z_{n}, z_{n}-x_{n}\right\rangle \geq 0, \quad \forall z \in C .
$$

Assume that $\left\{\alpha_{n}\right\},\left\{\beta_{n}\right\},\left\{\gamma_{n}\right\},\left\{\delta_{n}\right\},\left\{\lambda_{n}\right\},\left\{r_{n}\right\}$ satisfy the following restrictions:

(a) $\alpha_{n}+\beta_{n}+\gamma_{n}=1$,

(b) $0<a \leq \beta_{n} \leq b<1$ and $\sum_{n=1}^{\infty} \gamma_{n}<\infty$;

(c) $\liminf _{n \rightarrow \infty} r_{n}>0$ and $c \leq \lambda_{n} \leq d$, where $c, d \in(0,1 / L)$.

Then the sequence $\left\{x_{n}\right\}$ weakly converges to some point $\bar{x} \in \mathcal{F}$.

If $S=I$, where $I$ stands for the identity mapping, then Theorem 3.1 is reduced to the following.

Corollary 3.3 Let $C$ be a nonempty closed convex subset of $H$ and $A: C \rightarrow H$ be a $L$ Lipschitz continuous and monotone mapping. Let $F_{m}$ be a bifunction from $C \times C$ to $\mathbb{R}$ which satisfies (A1)-(A4). Let $N \geq 1$ denote some positive integer. Assume that $\mathcal{F}:=\bigcap_{m=1}^{N} E P\left(F_{m}\right) \cap$ $V I(C, A)$ is not empty. Let $\left\{\alpha_{n}\right\},\left\{\beta_{n}\right\},\left\{\gamma_{n}\right\},\left\{\delta_{n, 1}\right\}, \ldots,\left\{\delta_{n, N}\right\}$ be real number sequences in $(0,1)$. 
Let $\left\{\lambda_{n}\right\},\left\{r_{n, 1}\right\}, \ldots$, and $\left\{r_{n, N}\right\}$ be positive real number sequences. Let $\left\{e_{n}\right\}$ be a bounded sequence in $H$. Let $\left\{x_{n}\right\}$ be a sequence generated in the following manner:

$$
\left\{\begin{array}{l}
x_{1} \in H, \\
x_{n+1}=\alpha_{n} x_{n}+\beta_{n} \operatorname{Proj}_{C}\left(\sum_{m=1}^{N} \delta_{n, m} z_{n, m}-\lambda_{n} A y_{n}\right)+\gamma_{n} e_{n}, \quad n \geq 1, \\
y_{n}=\operatorname{Proj}_{C}\left(\sum_{m=1}^{N} \delta_{n, m} z_{n, m}-\lambda_{n} A \sum_{m=1}^{N} \delta_{n, m} z_{n, m}\right),
\end{array}\right.
$$

where $z_{n, m}$ is such that

$$
F_{m}\left(z_{n, m}, z\right)+\frac{1}{r_{n, m}}\left\langle z-z_{n, m}, z_{n, m}-x_{n}\right\rangle \geq 0, \quad \forall z \in C, \forall m \in\{1,2 \ldots, N\} .
$$

Assume that $\left\{\alpha_{n}\right\},\left\{\beta_{n}\right\},\left\{\gamma_{n}\right\},\left\{\delta_{n, 1}\right\}, \ldots,\left\{\delta_{n, N}\right\},\left\{\lambda_{n}\right\},\left\{r_{n, 1}\right\}, \ldots$, and $\left\{r_{n, N}\right\}$ satisfy the following restrictions:

(a) $\alpha_{n}+\beta_{n}+\gamma_{n}=1$

(b) $0<a \leq \beta_{n} \leq b<1$ and $\sum_{n=1}^{\infty} \gamma_{n}<\infty$;

(c) $\sum_{m=1}^{N} \delta_{n, m}=1$ and $0<c \leq \delta_{n, m} \leq 1$;

(d) $\liminf _{n \rightarrow \infty} r_{n, m}>0$ and $d \leq \lambda_{n} \leq e$, where $d, e \in(0,1 / L)$.

Then the sequence $\left\{x_{n}\right\}$ weakly converges to some point $\bar{x} \in \mathcal{F}$.

If $F_{m}(x, y) \equiv 0$ for all $x, y \in C$ and $r_{n, m} \equiv 1$, then Theorem 3.1 is reduced to the following.

Corollary 3.4 Let C be a nonempty closed convex subset of $H, S: C \rightarrow C$ be a nonexpansive mapping with a nonempty fixed point set, and $A: C \rightarrow H$ be a L-Lipschitz continuous and monotone mapping. Assume that $\mathcal{F}:=V I(C, A) \cap F(S)$ is not empty. Let $\left\{\alpha_{n}\right\},\left\{\beta_{n}\right\}$, and $\left\{\gamma_{n}\right\}$ be real number sequences in $(0,1)$. Let $\left\{\lambda_{n}\right\}$ be a positive real number sequence. Let $\left\{e_{n}\right\}$ be a bounded sequence in $H$. Let $\left\{x_{n}\right\}$ be a sequence generated in the following manner:

$$
\left\{\begin{array}{l}
x_{1} \in H, \\
x_{n+1}=\alpha_{n} x_{n}+\beta_{n} S \operatorname{Proj}_{C}\left(\operatorname{Proj}_{C} x_{n}-\lambda_{n} A y_{n}\right)+\gamma_{n} e_{n}, \quad n \geq 1, \\
y_{n}=\operatorname{Proj}_{C}\left(\operatorname{Proj}_{C} x_{n}-\lambda_{n} A \operatorname{Proj}_{C} x_{n}\right) .
\end{array}\right.
$$

Assume that $\left\{\alpha_{n}\right\},\left\{\beta_{n}\right\},\left\{\gamma_{n}\right\}$, and $\left\{\lambda_{n}\right\}$ satisfy the following restrictions:

(a) $\alpha_{n}+\beta_{n}+\gamma_{n}=1$,

(b) $0<a \leq \beta_{n} \leq b<1$ and $\sum_{n=1}^{\infty} \gamma_{n}<\infty$;

(c) $c \leq \lambda_{n} \leq d$, where $c, d \in(0,1 / L)$.

Then the sequence $\left\{x_{n}\right\}$ weakly converges to some point $\bar{x} \in \mathcal{F}$.

\section{Applications}

Theorem 4.1 Let $S: H \rightarrow H$ be a nonexpansive mapping with a nonempty fixed point set and $A: H \rightarrow H$ be a L-Lipschitz continuous and monotone mapping. Assume that $\mathcal{F}:=$ $A^{-1}(0) \cap F(S)$ is not empty. Let $\left\{\alpha_{n}\right\},\left\{\beta_{n}\right\}$, and $\left\{\gamma_{n}\right\}$ be real number sequences in $(0,1)$. Let $\left\{\lambda_{n}\right\}$ be a positive real number sequence. Let $\left\{e_{n}\right\}$ be a bounded sequence in $H$. Let $\left\{x_{n}\right\}$ be a sequence generated in the following manner:

$$
x_{1} \in H, \quad x_{n+1}=\alpha_{n} x_{n}+\beta_{n} S\left(x_{n}-\lambda_{n} A\left(x_{n}-\lambda_{n} A x_{n}\right)\right)+\gamma_{n} e_{n}, \quad n \geq 1 .
$$


Assume that $\left\{\alpha_{n}\right\},\left\{\beta_{n}\right\},\left\{\gamma_{n}\right\}$, and $\left\{\lambda_{n}\right\}$ satisfy the following restrictions:

(a) $\alpha_{n}+\beta_{n}+\gamma_{n}=1$,

(b) $0<a \leq \beta_{n} \leq b<1$ and $\sum_{n=1}^{\infty} \gamma_{n}<\infty$;

(c) $c \leq \lambda_{n} \leq d$, where $c, d \in(0,1 / L)$.

Then the sequence $\left\{x_{n}\right\}$ weakly converges to some point $\bar{x} \in \mathcal{F}$.

Proof Put $F_{m}(x, y) \equiv 0$ for all $x, y \in C$ and $r_{n, m} \equiv 1$. Notice that $A^{-1}(0)=V I(H, A)$ and $P_{H}=$ $I$, we easily find from Theorem 3.1 the desired conclusion.

Next, we consider the common zero point problem of two monotone mappings.

Theorem 4.2 Let $B: H \rightarrow 2^{H}$ a maximal monotone mapping and $A: H \rightarrow H$ be a $L$ Lipschitz continuous and monotone mapping. Assume that $\mathcal{F}:=A^{-1}(0) \cap B^{-1}(0)$ is not empty. Let $\left\{\alpha_{n}\right\},\left\{\beta_{n}\right\}$, and $\left\{\gamma_{n}\right\}$ be real number sequences in $(0,1)$. Let $\left\{\lambda_{n}\right\}$ be a positive real number sequence. Let $\left\{e_{n}\right\}$ be a bounded sequence in $H$. Let $\left\{x_{n}\right\}$ be a sequence generated in the following manner:

$$
x_{1} \in H, \quad x_{n+1}=\alpha_{n} x_{n}+\beta_{n} J_{r}^{B}\left(x_{n}-\lambda_{n} A\left(x_{n}-\lambda_{n} A x_{n}\right)\right)+\gamma_{n} e_{n}, \quad n \geq 1,
$$

where $J_{r}^{B}$ stands for the resolvent of B for each $r>0$. Assume that $\left\{\alpha_{n}\right\},\left\{\beta_{n}\right\},\left\{\gamma_{n}\right\}$, and $\left\{\lambda_{n}\right\}$ satisfy the following restrictions:

(a) $\alpha_{n}+\beta_{n}+\gamma_{n}=1$,

(b) $0<a \leq \beta_{n} \leq b<1$ and $\sum_{n=1}^{\infty} \gamma_{n}<\infty$;

(c) $c \leq \lambda_{n} \leq d$, where $c, d \in(0,1 / L)$.

Then the sequence $\left\{x_{n}\right\}$ weakly converges to some point $\bar{x} \in \mathcal{F}$.

Proof Put $F_{m}(x, y) \equiv 0$ for all $x, y \in C$ and $r_{n, m} \equiv 1$. Notice that $A^{-1}(0)=V I(H, A), F\left(J_{r}^{B}\right)=$ $B^{-1}(0)$, and $P_{H}=I$, we easily find from Theorem 3.1 the desired conclusion.

\section{Competing interests}

The authors declare that they have no competing interests.

Authors' contributions

All authors contributed equally and significantly in writing this paper. All authors read and approved the final manuscript.

Author details

'School of Mathematics and Information Science, North China University of Water Resources and Electric Power,

Zhengzhou, 450011, China. ${ }^{2}$ No.13 Zhongxue, Feng-Feng Kuangqu, Hangdan, 056000, China.

\section{Acknowledgements}

The authors are grateful to the editor and the referees for their valuable comments and suggestions which improved the contents of the article.

Received: 12 September 2012 Accepted: 27 December 2012 Published: 5 March 2013

\section{References}

1. Blum, E, Oettli, W: From optimization and variational inequalities to equilibrium problems. Math. Stud. 63, 123-145 (1994)

2. Combettes, PL, Hirstoaga, SA: Equilibrium programming in Hilbert spaces. J. Nonlinear Convex Anal. 6, 117-136 (2005)

3. Park, S: Some equilibrium problems in generalized convex spaces. Acta Math. Vietnam. 26, 349-364 (2001)

4. Ansari, QH, Schaible, S, Yao, JC: The system of generalized vector equilibrium problems with applications. J. Glob. Optim. 22, 3-16 (2002)

5. Lin, LJ, Yu, ZT, Ansari, QH, Lai, LP: Fixed point and maximal element theorems with applications to abstract economies and minimax inequalities. J. Math. Anal. Appl. 284, 656-671 (2003) 
6. Huang, NJ, Fang, YP: Strong vector F-complementary problem and least element problem of feasible set. Nonlinear Anal. 61, 901-918 (2005)

7. Park, S: On generalizations of the Ekeland-type variational principles. Nonlinear Anal. 39, 881-889 (2000)

8. Lin, L-J, Hsu, H-W: Existence theorems for systems of generalized vector quasiequilibrium problems and optimization problems. J. Glob. Optim. 37, 195-213 (2007)

9. Al-Homidan, S, Ansari, QH, Schaible, S: Existence of solutions of systems of generalized implicit vector variational inequalities. J. Optim. Theory Appl. 134(3), 515-531 (2007)

10. Konnov, IV, Yao, JC: Existence solutions for generalized vector equilibrium problems. J. Math. Anal. Appl. 223, 328-335 (1999)

11. Lin, LJ: Existence results for primal and dual generalized vector equilibrium problems with applications to generalized semi-infinite programming. J. Glob. Optim. 32, 579-597 (2005)

12. Kim, WK, Tan, KK: New existence theorems of equilibria and applications. Nonlinear Anal. 47, 531-542 (2001)

13. Lin, Z, Yu, J: The existence of solutions for the systems of generalized vector quasi-equilibrium problems. Appl. Math. Lett. 18, 415-422 (2005)

14. Husain, S, Gupta, S: A resolvent operator technique for solving generalized system of nonlinear relaxed cocoercive mixed variational inequalities. Adv. Fixed Point Theory 2, 18-28 (2012)

15. Lu, H, Wang, Y: Iterative approximation for the common solutions of a infinite variational inequality system for inverse-strongly accretive mappings. J. Math. Comput. Sci. 2, 1660-1670 (2012)

16. Qin, X, Cho, SY, Kang, SM: On hybrid projection methods for asymptotically quasi- $\phi$-nonexpansive mappings. Appl. Math. Comput. 215, 3874-3883 (2010)

17. Kotzer, T, Cohen, N, Shamir, J: Image restoration by a novel method of parallel projection onto constraint sets. Optim. Lett. 20, 1772-1774 (1995)

18. Byrne, C: A unified treatment of some iterative algorithms in signal processing and image reconstruction. Inverse Probl. 20, 103-120 (2008)

19. Qin, X, Cho, SY, Zhou, H: Common fixed points of a pair of non-expansive mappings with applications to convex feasibility problems. Glasg. Math. J. 52, 241-252 (2010)

20. Browder, FE: Nonexpansive nonlinear operators in a Banach space. Proc. Natl. Acad. Sci. USA 54, 1041-1044 (1965)

21. Cho, YJ, Qin, X: Systems of generalized nonlinear variational inequalities and its projection methods. Nonlinear Anal. 69, 4443-4451 (2008)

22. Qin, X, Cho, SY, Kang, SM: Strong convergence of shrinking projection methods for quasi- $\phi$-nonexpansive mappings and equilibrium problems. J. Comput. Appl. Math. 234, 750-760 (2010)

23. Qin, X, Cho, YJ, Kang, SM: Convergence theorems of common elements for equilibrium problems and fixed point problems in Banach spaces. J. Comput. Appl. Math. 225, 20-30 (2009)

24. Ye, J, Huang, J: Strong convergence theorems for fixed point problems and generalized equilibrium problems of three relatively quasi-nonexpansive mappings in Banach spaces. J. Math. Comput. Sci. 1, 1-18 (2011)

25. Zegeye, $\mathrm{H}$, Shahzad, N: Strong convergence theorem for a common point of solution of variational inequality and fixed point problem. Adv. Fixed Point Theory 2, 374-397 (2012)

26. Cho, SY, Kang, SM: Approximation of fixed points of pseudocontraction semigroups based on a viscosity iterative process. Appl. Math. Lett. 24, 224-228 (2011)

27. Lv, S, Wu, C: Convergence of iterative algorithms for a generalized variational inequality and a nonexpansive mapping. Eng. Math. Lett. 1, 44-57 (2012)

28. Cho, YJ, Petrot, N: Regularization and iterative method for general variational inequality problem in Hilbert spaces. J. Inequal. Appl. 2011, 21 (2011)

29. Cho, YJ, Petrot, N: Regularization method for Noor's variational inequality problem induced by a hemicontinuous monotone operator. Fixed Point Theory Appl. 2012, 169 (2012)

30. Cho, YJ, Argyros, IK, Petrot, N: Approximation methods for common solutions of generalized equilibrium, systems of nonlinear variational inequalities and fixed point problems. Comput. Math. Appl. 60, 2292-2301 (2010)

31. Qin, X, Chang, SS, Cho, YJ: Iterative methods for generalized equilibrium problems and fixed point problems with applications. Nonlinear Anal. 11, 2963-2972 (2010)

32. Qin, X, Shang, M, Su, Y: Strong convergence of a general iterative algorithm for equilibrium problems and variational inequality problems. Math. Comput. Model. 48, 1033-1046 (2008)

33. Rockafellar, RT: On the maximality of sums of nonlinear monotone operators. Trans. Am. Math. Soc. 149, 75-88 (1970)

34. Hao, Y, Cho, SY, Qin, X: Some weak convergence theorems for a family of asymptotically nonexpansive nonself mappings. Fixed Point Theory Appl. 2010, Article ID 218573 (2010)

35. Schu, J: Weak and strong convergence of fixed points of asymptotically nonexpansive mappings. Bull. Aust. Math. Soc. 43, 153-159 (1991)

36. Browder, FE: Fixed point theorems for noncompact mappings in Hilbert spaces. Proc. Natl. Acad. Sci. USA 53, 1272-1276 (1965)

37. Tan, KK, Xu, HK: Approximating fixed points of nonexpansive mappings by the Ishikawa iterative process. J. Math Anal. Appl. 178, 301-308 (1993)

doi:10.1186/1029-242X-2013-87

Cite this article as: Cheng and Zhang: Weak convergence theorems for common solutions of a system of equilibrium problems and operator equations involving nonexpansive mappings. Journal of Inequalities and Applications 2013 2013:87. 